\title{
Public sector seeks to bridge 'valley of death'
}

Even while prices for clinical-stage and earlier compounds rise as drug companies compete for assets to fill their pipelines, supporters of academic research have realized they need to pick up the burden of translational research. And as evidenced by recent academic funding schemes in the UK and Australia, that support is growing.

"Every public sector funding body around the world is getting into this area," explains Roberto

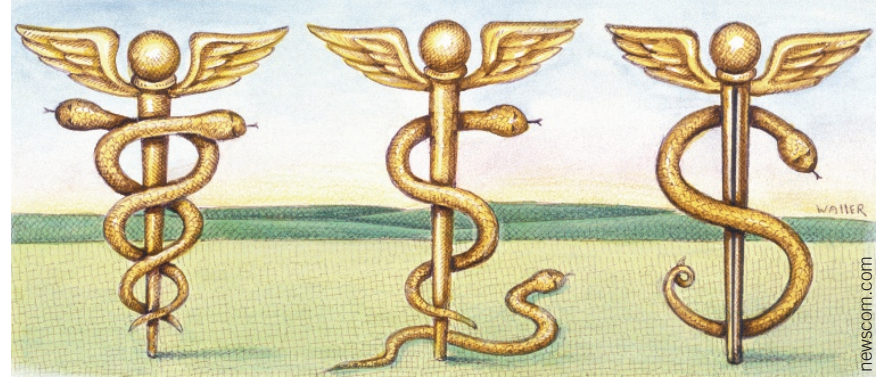

As evidenced by recent academic funding schemes in the US, Europe and Australia, support for translational research is ramping up.
Solari, chief executive of MRC

Technology, the technology transfer arm of the UK's Medical Research Council in London. Whereas 10 or 15 years ago it was extremely exciting to find a gene linked to a disease, "today that is commonplace," Solari points out."And in the past you could make claims and patent gene targets, but this is very difficult to do now."

The technology transfer gap has always been with us, but in drug discovery it has widened to form a valley of death between the traditional finishing point of research supported by an academic grant, and the sort of programs industry is interested in licensing or venture capitalists are prepared to back through a startup. Pharma and biotech companies prospecting for programs are no longer interested in naked biology. They demand proof that a target is relevant to treating a disease, that it can be modulated and that compounds for doing this are likely to be safe in humans. Moreover, they want this package gift wrapped with intellectual property rights.

Stephen Bunting, managing director of London-based Abingworth Management, which in January announced the closing at $\mathfrak{E 3 0 0}$ (\$587) million of its eighth life sciences fund, and the largest raised by a Europe-based venture capital firm, underscores the point. "We have invested in university or public sector startups, and are still keen to do it," he says. "But we are now more careful about what it is." Hence the call for greater government funding of translational research.

The US National Cancer Institute's RAID (Rapid Access to Interventional Development) program, set up in 1998 to speed new chemical entities though preclinical development, was one of the first organized attempts at this. The National Institutes of Health (NIH) set up a mirror scheme in 2005 under the $\mathrm{NIH}$ Roadmap strategy, its ongoing restructuring of medical research in the US. Drawing on the US example, similar programs are being put in place in Europe and elsewhere.
The most recent example, in Australia, is just being unveiled. In January 2007, the Cooperative Research Centre for Cancer Therapeutics (CRC-CT) in Canberra announced it will bring together eight Australian cancer research institutes and two services companies, with London's CRT Ltd., the technology transfer arm of Europe's leading cancer charity, Cancer Research UK. CRT will spend an initial AU\$76 (\$136.3) million over seven years to fund the development of seven or eight small molecules to the point where they can be outlicensed. The chairman of CRC-CT Dick Fox says, "Our goal is to develop a sustainable development and commercialization company for cancer therapeutics."

The EU, for its part, has been steadily increasing its support for translational research. In 2005, the European Investment Fund (EIF) carried out a study of technology transfer and concluded that Europe is suffering "a market failure" in this arena. Among other measures, this prompted the EIF to agree to a $€ 8$ ( $\$ 10.4)$ million partnership with the University of Leuven in Belgium to set up a center for drug design and discovery and find compounds for targets from the university and externally. Similarly, EMBLEM, the technology transfer arm of the European Molecular Biology Laboratory (EMBL) in Heidelberg, Germany, has a small fund for screening of hits to EMBL targets and their preclinical development. And one of the earlier movers in Europe, the UK's MRC, established an in-house screening facility four years ago, subsequently adding medicinal chemistry and antibody humanization skills. The Medical Research Council is putting $\mathfrak{£} 4$ (\$7.9) million per annum into its drug discovery group.

But these schemes are paltry next to the $£ 91$ (\$178.9) million seeding drug discovery program announced by the research charity the Wellcome Trust in London in January 2007, which will support 30 UK-based programs over the next five years.
Ted Bianco, director of technology transfer at the Wellcome Trust, says the objective of Seeding Drug Discovery is to address unmet medical need. Potential market size is not a consideration and the Trust has no financial motive, though it will get a return if a product is a commercial success. The first three programs-which have received backing of between $£ 2.3-3.8$ ( $\$ 4.5$ 7.4) million each-are to develop a protein kinase inhibitor for treating lung cancer and an antiinfective against antibiotic-resistant staphylococcal infections, and to formulate a long-lasting version of a natural gut hormone involved in appetite control as an anti-obesity product.

"Our general stance is that we don't portfolio manage," says Bianco. "We didn't make a prior decision to support these three areas; we are looking for scientific excellence backed by a good development plan."

Whereas the Wellcome Trust selects projects from an open field of applicants, the MRC works solely on its own research. "We are at the riskier end: we don't do followers and we won't do me too's," says Solari. In the past two years the unit has looked at around 55 targets; last year six were selected for screening, and the aim is to have two hit-to-lead programs running at any one time.

The lead programs to date at MRC are in malaria and tuberculosis. Concurrently, the antibody humanization group is working on two antibodies, with the lead designed to neutralize hepatitis C.

In-licensing activity by pharma and biotech over the past year may appear to belie concerns about the drug discovery gap. There is increasing competition, and with advanced programs in short supply, deals are being done around early clinical and even preclinical products: witness the $\$ 40$ million-plus up-front payments (before subsequent milestones and royalties kick in) that biotechs Exelixis and Seattle Genetics received recently for compounds that have yet to show clinical proof of concept (News in Brief, p. 269).

But the MRC's Solari laments that the industry is interested only in druggable targets. "There are whole areas of human health and biology that are not related to druggable targets," he said, adding, "There continues to be a growing wealth of really interesting and potentially significant basic biology that won't get onto the radar screen of industry."

Nuala Moran, London 